\title{
Loop electrosurgical excision procedure combined with cold coagulation for cervical intraepithelial neoplasia and adenocarcinoma in-situ: a feasible treatment with a low risk of residual/ recurrent disease
}

Eun Jung Yang ${ }^{1}$, Nae Ry Kim", Ji Yeon Choi ${ }^{1}$, Wook Youn Kim² and Sun Joo Lee ${ }^{1 *}$ (i)

\begin{abstract}
Objective: This study was performed to evaluate the significance of positive resection margins (RMs) with the loop electrosurgical excision procedure combined with cold coagulation (LEEP with CC) as a definitive treatment for patients with cervical intraepithelial neoplasia (CIN) and adenocarcinoma in-situ.

Methods: We retrospectively reviewed 467 patients who underwent LEEP with CC. A right-angled triangular loop in a single pass followed by a CC $\left(120^{\circ} \mathrm{C}\right)$ to the cone bed for 10 to $20 \mathrm{~s}$ was used. Pathology reports and clinical data were obtained and evaluated.

Results: Histopathology evaluation of LEEP tissue samples revealed the presence of CIN 1 in 69, CIN 2/3 in 366, AIS in 5 and invasive carcinoma in 16 (microinvasive squamous cell carcinoma (SCC) and invasive SCC, 13 and 3) patients. Margins were positive in 66 (14.5\%) cases: 0 in CIN 1, 54 in CIN 2/3 (12.4\%), 1 in AIS (20.0\%) and 11 in microinvasive/invasive SCC (68.8\%). Although 54 CIN2/3 patients with positive RMs did not undergo additional treatment, 1 of these (1.9\%) was confirmed to have residual CIN3 at the first follow-up. Two of 8 (25.0\%) microinvasive SCC patients with positive RMs were confirmed to have residual diseases (1 microinvasive SCC and 1 invasive SCC) after hysterectomy. Four out of 360 (1 positive RM, 3 negative RM) CIN cases recurred during the study period.
\end{abstract}

Conclusions: These results suggest that CIN patients with positive RMs after LEEP with CC may be followed up without additional treatment.

Keywords: Cervical intraepithelial neoplasia, Microinvasive carcinoma, Loop electrosurgical excision procedure, Cold coagulation, Resection margin

\footnotetext{
* Correspondence: Isj671121@gmail.com

'Department of Obstetrics and Gynecology, Konkuk University Hospital,

Konkuk University School of Medicine, 120-1 Neungdong-ro, Hwayang-dong, Gwangjin-gu, Seoul 05030, Korea

Full list of author information is available at the end of the article
}

(c) The Author(s). 2020 Open Access This article is licensed under a Creative Commons Attribution 4.0 International License, which permits use, sharing, adaptation, distribution and reproduction in any medium or format, as long as you give appropriate credit to the original author(s) and the source, provide a link to the Creative Commons licence, and indicate if changes were made. The images or other third party material in this article are included in the article's Creative Commons licence, unless indicated otherwise in a credit line to the material. If material is not included in the article's Creative Commons licence and your intended use is not permitted by statutory regulation or exceeds the permitted use, you will need to obtain permission directly from the copyright holder. To view a copy of this licence, visit http://creativecommons.org/licenses/by/4.0/. The Creative Commons Public Domain Dedication waiver (http://creativecommons.org/publicdomain/zero/1.0/) applies to the data made available in this article, unless otherwise stated in a credit line to the data. 


\section{Introduction}

Cervical intraepithelial neoplasia (CIN) has been treated in many different ways including various ablative and excisional procedures [1]. Treating women with CIN reduces the risk of invasive cervical cancer by $95 \%[2,3]$. The loop electrosurgical excision procedure (LEEP) is a cervical conization procedure using an electrosurgical loop. Since the introduction of LEEP in 1989, it has become one of the most frequently performed gynecological procedures $[4,5]$.

Previous studies have demonstrated that LEEP is simpler [6] and yields short- and long-term results that are identical to those obtained with more aggressive cold knife conization [6-8]. Although LEEP has a low surgical morbidity [9], some patients experience complications such as postoperative hemorrhaging. To minimize hemorrhagic complications, Allam et al introduced LEEP combined with cold coagulation (LEEP with CC) [10]. This study reported a lower rate of post-treatment bleeding compared with the rates of other LEEP methods. Moreover, the authors suggested that treatment of CIN using LEEP and CC combined could have less abnormal cervical cytologic findings in women who had incomplete excision of their initial lesion compared to LEEP alone. Meanwhile, previous studies reported positive margin rates of 16 to $46.3 \%$ after LEEP [7, 11-13]. Although several earlier studies have reported that replicate surgical specimens of patients with involved resection margins (RMs) frequently have no residual neoplasia [14-17], the margin status of conization specimens is considered to be an important predictor of residual neoplasia $[18,19]$. Therefore, the American Society for Colposcopy and Cervical Pathology (ASCCP) guidelines recommend "cervical cytology and endocervical curettage at 4-6 months is preferred, but repeat excision or hysterectomy is acceptable" for the cases of "CIN 2, 3 with positive margins" [20].

The present study was designed to evaluate the relation of margin status with residual/recurrent disease in patients treated by LEEP with CC in routine practice. All cases were diagnosed as CIN or adenocarcinoma in-situ (AIS) with colposcopically directed biopsies before LEEP.

\section{Material and methods}

We retrospectively reviewed the medical records and pathology reports of patients who underwent LEEP with CC for the treatment of CIN at Konkuk University Hospital in Seoul, Korea, from August 2005 to December 2018. The inclusion criteria were age $\geq 21$ years old, not pregnant, and preoperatively confirmed as having CIN or AIS by colposcopically directed biopsy. Patients with microinvasive or invasive cancer diagnosed before LEEP were excluded from the study. The RM status had been determined on all cases that underwent LEEP with CC. However, cases lost to follow-up after treatment were excluded from the residual/recurrent disease analysis.
Colposcopically directed biopsies were performed on acetowhite areas. Endocervical curettage (ECC) biopsies were performed when transformation zones could not be evaluated by colposcopy. When acetowhite areas were not seen, random cervical punch biopsies in four quadrants together with ECC biopsies were performed. CIN1 cases were recommended for LEEP if they had persistent lesions for more than 2 years or wanted surgery due to concerns regarding cancer within 2 years. Patients with CIN2/3 or AIS underwent LEEP unless they wanted a hysterectomy. When higher grades of CIN, microinvasive and invasive cancer were reported pathologically after LEEP, the diagnoses were upgraded according to the pathology reports. RMs were considered positive in cases where CIN2/3 or more was present on the inked margin [21]. We initially recommended hysterectomy to patients with AIS or microinvasive squamous cell carcinoma (SCC). However, if patients wanted to preserve their fertility, they were followed up without retreatment regardless of the RM status, in accordance with the results of a previous study [14]. Patients with invasive SCC or adenocarcinoma underwent radical hysterectomy or trachelectomy. Residual disease was defined as detection of CIN2/3 or a higher-grade lesion during the first 6 months of follow-up [22]. Recurrence was defined as detection of CIN2/3 or higher-grade lesion thereafter [22]. Patients with residual/recurrent diseases underwent management according to ASCCP guidelines [20, 23].

\section{Loop electrosurgical excision procedure combined with cold coagulation}

LEEP with CC was performed on an in-patient basis using general anesthesia (monitored anesthesia care) by an expert gynecologic oncologist (SJ LEE). LEEP used a right-angled, triangular loop in a single pass with a 3.8$\mathrm{MHz}$ radiosurgery unit (Ellman ${ }^{\circ}$ International, Inc., NY, USA). A cold coagulator $\left(120^{\circ} \mathrm{C}\right)$ (Eurosurgical ${ }^{\circ}$, Guildford, UK) was applied to the cone bed for 10 to $20 \mathrm{~s}$ after the excision for hemostasis and destruction of any residual lesion. Before the procedure, $5 \%$ acetic acid was applied to the cervix for 1 to $2 \mathrm{~min}$ to localize cervical lesions. Hemostatic agents (e.g., Monsel's solution or fibrin sealant) were not applied after LEEP.

\section{Follow-up}

Negative RM CIN cases were routinely followed up at 4 to 6 , and 12 months with pap smear and/or HPV DNA testing. After 12 months, routine annual follow-up was recommended according to guidelines. Positive RM CIN cases were evaluated with pap smear, HPV DNA testing and ECC at 4 to 6 months. In cases where pap smear and HPV DNA testing were negative at 12 months, routine annual follow-up was subsequently pursued. 
This study was approved by the institutional review board at Konkuk University Hospital.

\section{Statistical analysis}

Categorical variables were assessed with the $x^{2}$ test using $\mathrm{IBM}^{\circ} \mathrm{SPSS}^{\circ}$ statistics 22.0 software (IBM SPSS Statistics, Chicago, IL, USA). A $P$-value $<0.05$ was considered statistically significant.

\section{Results}

\section{Clinical data}

During the study period, 456 patients underwent LEEP using a right-angled triangular loop with CC. The median age of patients was 38 years (range, 21 to 80 years). After LEEP, 19 of 98 (19.4\%) CIN1 cases were upgraded to CIN2/3 according to the pathology report. Forty of 89 (44.9\%) CIN2 cases were upgraded according to the pathology report as follows: 38 to CIN3 and 1 each to AIS and to microinvasive SCC. Fifteen of 226 (6.6\%) CIN3 cases were upgraded to 12 microinvasive SCC and 3 invasive SCC following LEEP. Seventy-five (16.4\%) CIN cases were lost to follow-up after LEEP. All patients who were diagnosed postoperatively as having AIS, microinvasive SCC or invasive SCC were followed up at regular intervals for a median period of 48 months (range, 4 to 157 months) (Table 1). During the study period, 21 patients (5 AIS, 13 microinvasive SCC, 3 invasive SCC) were free of recurrent disease.

\section{Resection margins and residual diseases}

After LEEP, 66 (14.5\%) of 456 patients had positive RMs. Of these, 22 (4.8\%) involved the exocervix, 39 (8.6\%) the endocervix and 5 (1.1\%) both the exocervix and endocervix (Table 1). Endocervical RM was defined here as endocervical RM and/or deep RM. CIN1 cases had no positive RMs, whereas 54 (15.2\%) of $356 \mathrm{CIN} 2 / 3$ cases, 1 (20.0\%) of 5 AIS cases, 8 (61.5\%) of 13 microinvasive SCC cases, and 3 (100.0\%) of 3 invasive SCC cases had positive RMs. Higher grades of disease tended to have higher rates of positive RMs.

Residual disease was analyzed in 381 patients who were followed up continuously in our institute (Tables 2 and 3). One of 44 (2.3\%) CIN2/3 patients with positive RMs revealed residual CIN3 at 4 months and underwent LEEP. The remaining 43 patients were followed up without treatment. All patients showed no residual disease during the study period. One AIS patient with positive RM underwent hysterectomy immediately, but no residual lesions were reported after hysterectomy. However, one AIS patient with negative RM revealed residual AIS after hysterectomy. Three other negative RM AIS patients had no residual disease during follow-up. Seven of 8 microinvasive SCC patients with positive RMs underwent hysterectomy within 1 month after LEEP; one patient had microinvasive SCC and
Table 1 Characteristics of patients who underwent loop electrosurgical excision procedure combined with cold coagulation

\begin{tabular}{ll}
\hline Parameter & Results $(\boldsymbol{n}=\mathbf{4 5 6})$ \\
\hline Median age (range) in years & $38.0(21.0-80.0)$ \\
Median follow-up period (range) in months & \\
AIS/Microinvasive SCC/invasive SCC & $48.0(4.0-157.0)$ \\
Histologic diagnosis before LEEP, $\mathrm{n}(\%)$ & \\
CIN1 & $98(21.5)$ \\
CIN2/3 & $128 / 226(77.6)$ \\
AIS & $4(0.9)$ \\
Final histologic diagnosis after LEEP, $n(\%)$ & \\
CIN1 & $79(17.3)$ \\
CIN2/3 & $89 / 267(78.1)$ \\
AIS & $5(1.1)$ \\
Microinvasive SCC & $13(2.9)$ \\
Invasive SCC & $3(0.7)$ \\
Positive resection margin after LEEP, $n(\%)$ & $66(14.5)$ \\
aEndocervical margin & $39(8.6)$ \\
Exocervical margin & $22(4.8)$ \\
Both margins & $5(1.1)$ \\
\hline AIS adenocaring
\end{tabular}

AIS adenocarcinoma in-situ, SCC squamous cell carcinoma, CIN cervical intraepithelial neoplasia

aEndocervical margin; defined as endocervical resection margin and/or deep resection margin

another had invasive SCC. One microinvasive SCC case with positive RMs (endocervix and exocervix) was followed up without additional surgical treatment. This patient has shown 'no evidence of disease' for 46 months. Five negative RM microinvasive SCC cases (3 underwent hysterectomy, 2 without additional surgical treatment) had no residual disease during the study period. Three invasive SCC patients with positive RMs were diagnosed as having no residual disease after radical surgery.

\section{Recurrent disease during follow-up period}

Although there were no positive RM cases in the CIN1 group, one case developed recurrent CIN3 within 12 months (Table 4). In the CIN2/3 group, 3 cases (one positive RM and 2 negative RM) were diagnosed as having recurrent CIN3. When recurrent CIN1 cases were included $(\mathrm{CIN} 1+\mathrm{CIN} 2 / 3)$, the positive RM group showed a higher rate of recurrence compared to the negative RM group $(9.1 \%$ vs $4.9 \%)$. Nevertheless, there was no statistical significance between these two groups $(P=0.298)$ (Table 4). AIS, microinvasive SCC and invasive SCC cases showed no recurrent disease during the follow-up period.

\section{Discussion}

We present here an analysis of 381 women who underwent LEEP using a right-angled triangular loop 
Table 2 Final diagnosis and resection margin status after LEEP, excluding cases lost to follow-up $(n=381)$

\begin{tabular}{|c|c|c|}
\hline Diagnosis after-LEEP, $n$ & Positive RM, n (\%) & Residual disease, $\mathrm{n}(\%)$ \\
\hline CIN1, 70 & 0 & 0 \\
\hline \multirow[t]{4}{*}{ CIN2/3, 290} & $44(15.2)$ & $1(0.3)$ \\
\hline & Endocervix $25^{\mathrm{a}}$ & 1 (CIN3, LEEP at $4 \mathrm{mo})$ \\
\hline & Exocervix $18^{\mathrm{a}}$ & 0 \\
\hline & Both margins $1^{\mathrm{a}}$ & 0 \\
\hline \multirow[t]{4}{*}{ AIS, 5} & $1(20.0)$ & 0 \\
\hline & Endocervix $1^{\mathrm{b}}$ & 0 \\
\hline & Exocervix 0 & \\
\hline & Both margins 0 & \\
\hline \multirow[t]{4}{*}{ Microinvasive SCC, 13} & $8(61.5)$ & $2(15.4)$ \\
\hline & Endocervix 5 & $1^{\mathrm{b}}$ (microinvasive SCC) \\
\hline & Exocervix 0 & \\
\hline & Both margins 3 & $1^{\mathrm{b}}$ (invasive SCC) \\
\hline \multirow[t]{4}{*}{ Invasive SCC, 3} & $3(100.0)$ & 0 \\
\hline & Endocervix $2^{c}$ & 0 \\
\hline & Exocervix 0 & \\
\hline & Both margins $1^{c}$ & 0 \\
\hline
\end{tabular}

LEEP loop electrosurgical excision procedure, $R M$ resection margin, CIN cervical intraepithelial neoplasia, AIS adenocarcinoma in-situ, SCC squamous cell carcinoma afollow-up without additional LEEP (pap smear, HPV DNA testing and endocervical curettage at 4-6 months);

bysterectomy

'radical hysterectomy, radical trachelectomy

combined with CC for CIN confirmed preoperatively by colposcopically directed biopsy. This study found a low rate of residual disease $(0.8 \%)$, despite the fact this procedure showed a positive RM rate of $14.7 \%$. Of note, CIN $1 / 2 / 3$ and AIS cases showed a low rate of only $0.3 \%$
(1/365) with residual disease. During the follow-up period, recurrent disease occurred in $1.1 \%$ of cases (4/ 365,1 with positive RM and 3 with negative RM). Based on these results, we suggest that positive RM cases with a final diagnosis of CIN or AIS and who undergo LEEP

Table 3 Characteristics of patients with positive resection margins after loop electrosurgical excision procedure combined with cold coagulation

\begin{tabular}{|c|c|c|c|c|c|}
\hline \multirow[b]{2}{*}{ Age } & \multirow[b]{2}{*}{ Diagnosis } & \multicolumn{2}{|c|}{ Resection margins } & \multirow[b]{2}{*}{ Residual tumor } & \multirow[b]{2}{*}{ Patient status } \\
\hline & & endocervix & exocervix & & \\
\hline 50 & AIS & + & - & $\mathrm{No}^{\mathrm{b}}$ & NED, 85 mo \\
\hline 46 & Microinvasive SCC & + & + & Invasive $\mathrm{SCC}^{\mathrm{b}}$ & NED, 19 mo \\
\hline 36 & Microinvasive SCC & + & - & $\mathrm{No}^{\mathrm{b}}$ & NED, $28 \mathrm{mo}$ \\
\hline 49 & Microinvasive SCC & + & - & $\mathrm{No}^{b}$ & NED, $151 \mathrm{mo}$ \\
\hline 37 & Microinvasive SCC & + & + & $\mathrm{No}^{\mathrm{a}}$ & NED, 46 mo \\
\hline 60 & Microinvasive SCC & + & - & $\mathrm{CIN} 1^{\mathrm{b}}$ & NED, $116 \mathrm{mo}$ \\
\hline 46 & Microinvasive SCC & + & + & $\mathrm{No}^{b}$ & NED, $156 \mathrm{mo}$ \\
\hline 57 & Microinvasive SCC & + & - & Microinvasive ${ }^{b}$ & NED, 14 mo \\
\hline 40 & Microinvasive SCC & + & - & $\mathrm{No}^{\mathrm{b}}$ & NED, 4 mo \\
\hline 56 & Invasive SCC & + & + & $\mathrm{CIN}_{1}^{\mathrm{c}}$ & NED, 139 mo \\
\hline 35 & Invasive SCC & + & - & $\mathrm{No}^{\mathrm{c}}$ & NED, 48 mo \\
\hline 41 & Invasive SCC & + & - & $\mathrm{No}^{\mathrm{C}}$ & NED, 104 mo \\
\hline
\end{tabular}

SCC squamous cell carcinoma, NED no evidence of disease

${ }^{\text {a }}$ follow-up without additional treatment

bysterectomy

cradical hysterectomy, radical trachelectomy 
Table 4 Abnormal histology during follow-up period $(n=381)$

\begin{tabular}{llll}
\hline & \multicolumn{2}{l}{ Abnormal histology during follow-up period } \\
\hline Diagnosis after-LEEP & Positive RM, (n/\%) & Negative RM, (n / \%) & P-value \\
CIN1 & No case & $\mathrm{CIN1}^{\mathrm{a}}(2 / 2.9)$ & - \\
& & $\mathrm{CIN3}^{\mathrm{c}}(1 / 1.4)$ & \\
$\mathrm{CIN2/3}$ & $\mathrm{CIN1}^{\mathrm{a}, \mathrm{b}}(3 / 6.8)$ & $\mathrm{CIN1}^{\mathrm{a}, \mathrm{b}, \mathrm{c}}(10 / 4.1)$ & 0.298 \\
& $\mathrm{CIN3}^{\mathrm{b}}(1 / 2.3)$ & $\mathrm{CIN3}^{\mathrm{b}, \mathrm{c}}(2 / 0.8)$ & \\
AIS & $\mathrm{NED}$ & $\mathrm{CIN1}^{\mathrm{b}}(1 / 25.0)$ & - \\
Microinvasive SCC & NED & NED & - \\
Invasive SCC & NED & No cases & - \\
\hline
\end{tabular}

a follow-up without additional treatment

bLEEP

chysterectomy

${ }^{d}$ radical hysterectomy, radical

with CC can be followed up by pap, HPV DNA testing and ECC without re-excision or hysterectomy. However, the present study indicates that patients diagnosed as having microinvasive SCC with positive RMs following LEEP with CC may have a higher rate of residual disease (15.4\%, 2/13) than CIN/ AIS cases. Moreover, 2 cases were reported as invasive SCC and microinvasive SCC after hysterectomy. In spite that 3 microinvasive SCC cases without additional treatment ( 1 with positive RM, 2 with negative RMs) revealed no residual/recurrent disease during follow-up, we suggest that microinvasive SCC cases with negative RM who undergo LEEP with CC can be followed up without additional surgical treatment.

The present study showed a positive RM frequency of $14.5 \%$, which was similar to previous studies using LEEP. However, residual/recurrent diseases were diagnosed less frequently. Moreover, the current study demonstrated that exocervical or endocervical RMs did not have different effects on the residual/recurrent status. We believe this was due to the use of a right-angled triangular loop in a single pass and the cold coagulator used in our study. Miroshnichenko et al [24] reported that LEEP using a ring-shaped loop was less likely to yield a single intact specimen and that an increase in the number of specimens obtained had a statistically significant negative effect on pathology interpretation. Adequate pathology interpretation using appropriate specimens is required to reduce residual tumors. Matsumura et al [25] previously suggested that one adequate specimen could be obtained in the majority of cases by using a triangular probe and a rigid linear electrode. This is because its relatively large size allows resection of the entire transformation zone and because its linearity allows resection of any lesion extending into the endocervix [25]. Despite having similar positive RM rates, the present study may have more accurate data compared to other previous reports using a ring-shaped loop. Secondly, combined cold coagulator after LEEP might be beneficial both as a hemostatic technique and for reducing the proportion of abnormal smears during followup [10]. From the literature, approximately 30 to $50 \%$ of cases with involved margins were found to have no residual tumor upon subsequent hysterectomy [17, 26, 27]. This likely indicates the presence of a mechanism that clears residual tumor cells in remnant cervical tissue after conization. Paterson et al [26] and White et al [28] suggested that local activation of cellular immunity after conization causes the regression of residual tumor cells. Additionally, hemostatic measures such as cold coagulation may play a role in destroying residual tumor at the RM, or may influence regression to normal tissue [14].

A strong point of our study was the analysis of all cases that had been treated according to standard practice guidelines at a new hospital since opening. Therefore, we believe the results were not biased due to operator or treatment policy factors. Secondly, the analysis was performed on CIN or AIS cases that were confirmed by colposcopically directed biopsy. Hence, preoperatively selected cases are likely to provide reliability to the study results.

There are however several limitations to this study. Firstly, this was a retrospective case series with a relatively small number of patients. The conclusion of this study was determined by low rate of recurrence. Second, the study did not focus on postoperative complications such as postoperative bleeding, menstruation bleeding volume, pregnancy or preterm delivery. Although a larger volume or destruction by cold coagulator can result in a lower rate of positive RMs, the postoperative complications could increase. However, previous studies using a right-angled triangular loop and/or cold coagulator revealed similar or fewer postoperative complications compared with studies using a ring-shaped loop [14, 25]. Therefore, we believe the rate of postoperative complications in the present study may have been reasonable.

In conclusion, positive RM CIN or AIS cases that undergo LEEP using a right-angled triangular loop combined with CC can be followed up by pap, HPV DNA testing and ECC without re-excision or hysterectomy. However, despite the low rate of residual tumor, reexcision or hysterectomy could be safer for patients diagnosed with positive RM microinvasive SCC or invasive SCC after LEEP. Further large-scale studies will be required to allow more firm conclusions to be drawn.

\footnotetext{
Abbreviations

RMs: Resection margins; LEEP: Loop electrosurgical excision procedure; CC: Cold coagulation; CIN: Cervical intraepithelial neoplasia; SCC: Squamous cell carcinoma; ASCCP: American Society for Colposcopy and Cervical Pathology; AIS: Adenocarcinoma in-situ; ECC: Endocervical curettage
} 


\section{Authors' contributions}

EJ: Protocol/project development, Manuscript writing/editing. NR: Protocol/ project development, Data collection and anlysis. JY: Data collection and data management, Data analysis. WY: Protocol/project development, Data collection and data management. SJ: Protocol/project development, Data anlysis, Manuscript writing/editing. The author(s) read and approved the final manuscript.

\section{Funding}

Not applicable.

\section{Availability of data and materials}

All the relevant data for this analysis have been presented in the body of this manuscript and the associated tables. The original data sources and the dataset used in this analysis is available upon reasonable request to the corresponding author.

\section{Ethics approval and consent to participate}

The study was approved by the Konkuk university medical center Institutional Review Board.

\section{Consent for publication}

The manuscript was approved for publication by all authors.

\section{Competing interests}

The authors declare that they have no competing interests.

\section{Author details}

'Department of Obstetrics and Gynecology, Konkuk University Hospital, Konkuk University School of Medicine, 120-1 Neungdong-ro, Hwayang-dong, Gwangjin-gu, Seoul 05030, Korea. ${ }^{2}$ Department of Pathology, KonKuk University Hospital, Seoul, Republic of Korea.

Received: 31 July 2020 Accepted: 23 September 2020

\section{Published online: 06 October 2020}

\section{References}

1. Hanau CA, Bibbo M. The case for cytologic follow-up after LEEP. Acta Cytol. 1997;41:731-6 https://doi.org/10.1159/000332695.

2. Soutter WP, de Barros LA, Fletcher A, Monaghan JM, Duncan ID, Paraskevaidis E, et al. Invasive cervical cancer after conservative therapy for cervical intraepithelial neoplasia. Lancet. 1997;349:978-80 https://doi.org/10. 1016/S0140-6736(96)08295-5.

3. Naumann RW, Bell MC, Alvarez RD, Edwards RP, Partridge EE, Helm CW, et al. LLETZ is an acceptable alternative to diagnostic cold-knife conization. Gynecol Oncol. 1994;55:224-8 https://doi.org/10.1006/gyno.1994.1281.

4. Prendiville W, Cullimore J, Norman S. Large loop excision of the transformation zone (LLETZ). A new method of management for women with cervical intraepithelial neoplasia. Br J Obstet Gynaecol. 1989;96:1054-60 https://doi.org/10.1111/j.1471-0528.1989.tb03380.x.

5. Kim K, Park SI, Kim BJ, Kim MH, Choi SC, Ryu SY, et al. Efficacy of fibrin sealant in reducing hemorrhage after a loop electrosurgical excision procedure. Gynecol Obstet Investig. 2012;74:1-5 https://doi.org/10.1159/ 000333266.

6. Mathevet P, Chemali E, Roy M, Dargent D. Long-term outcome of a randomized study comparing three techniques of conization: cold knife, laser, and LEEP. Eur J Obstet Gynecol Reprod Biol. 2003;106:214-8 https:// doi.org/10.1016/S0301-2115(02)00245-2.

7. Duggan BD, Felix JC, Muderspach LI, Gebhardt JA, Groshen S, Morrow CP, et al. Cold-knife conization versus conization by the loop electrosurgical excision procedure: a randomized, prospective study. Am J Obstet Gynecol. 1999;180:276-82 https://doi.org/10.1016/50002-9378(99)70200-0.

8. Mathevet P, Dargent D, Roy M, Beau G. A randomized prospective study comparing three techniques of conization: cold knife, laser, and LEEP. Gynecol Oncol. 1994;54:175-9 https://doi.org/10.1006/gyno.1994.1189.

9. Wright TC Jr, Gagnon S, Richart RM, Ferenczy A. Treatment of cervical intraepithelial neoplasia using the loop electrosurgical excision procedure. Obstet Gynecol. 1992;79:173-8.

10. Allam M, Paterson A, Thomson A, Ray B, Rajagopalan C, Sarkar G. Large loop excision and cold coagulation for management of cervical intraepithelial neoplasia. Int J Gynaecol Obstet. 2005;88:38-43 https://doi.org/10.1016/j.ijgo. 2004.09.019.

11. Leimbacher B, Samartzis N, Imesch P, Dedes KJ, Fink D, Canonica C. Inpatient and outpatient loop electrosurgery excision procedure for cervical intraepithelial neoplasia: a retrospective analysis. Arch Gynecol Obstet. 2012; 285:1441-5 https://doi.org/10.1007/s00404-011-2148-7.

12. Sutthichon P, Kietpeerakool C. Perioperative complications of an outpatient loop electrosurgical excision procedure: a review of 857 consecutive cases. Asian Pac J Cancer Prev. 2009;10:351-4.

13. Tillmanns TD, Falkner CA, Engle DB, Wan JY, Mannel RS, Walker JL, et al. Preoperative predictors of positive margins after loop electrosurgical excisional procedure-cone. Gynecol Oncol. 2006;100:379-84 https://doi.org/ 10.1016/j.ygyno.2005.09.015.

14. Lee SJ, Kim WY, Lee JW, Kim HS, Choi YL, Ahn GH, et al. Conization using electrosurgical conization and cold coagulation for international federation of gynecology and obstetrics stage IAI squamous cell carcinomas of the uterine cervix. Int J Gynecol Cancer. 2009;19:407-11 https://doi.org/10.1111/ IGC.0b013e3181a1a297.

15. Chang DY, Cheng WF, Torng PL, Chen RJ, Huang SC. Prediction of residual neoplasia based on histopathology and margin status of conization specimens Gynecol Oncol. 1996;63:53-6 https:/doi.org/10.1006/gyno.1996.0277.

16. Lapaquette TK, Dinh TV, Hannigan EV, Doherty MG, Yandell RB, Buchanan VS. Management of patients with positive margins after cervical conization. Obstet Gynecol. 1993;82:440-3.

17. Reich O, Lahousen M, Pickel H, Tamussino K, Winter R. Cervical intraepithelial neoplasia III: long-term follow-up after cold-knife conization with involved margins. Obstet Gynecol. 2002;99:193-6 https://doi.org/10. 1016/S0029-7844(01)01683-0.

18. Gurgel MS, Bedone AJ, Andrade LA, Panetta K. Microinvasive carcinoma of the uterine cervix: histological findings on cone specimens related to residual neoplasia on hysterectomy. Gynecol Oncol. 1997;65:437-40 https:// doi.org/10.1006/gyno.1997.4665.

19. Roman LD, Felix JC, Muderspach LI, Agahjanian A, Qian D, Morrow CP. Risk of residual invasive disease in women with microinvasive squamous cancer in a conization specimen. Obstet Gynecol. 1997;90:759-64 https://doi.org/ 10.1016/50029-7844(97)00414-6.

20. Massad LS, Einstein MH, Huh WK, Katki HA, Kinney WK, Schiffman M, et al. 2012 updated consensus guidelines for the management of abnormal cervical cancer screening tests and cancer precursors. J Low Genit Tract Dis. 2013;17:S1-S27.

21. Shim SH, Lee SJ, Yang SW, Lim JY, Cho SH, Kim WY, et al. Comparison of loop electrosurgical excision procedure using a ring-shaped loop versus a right-angled triangular loop. J Reprod Med. 2017;62:265-70.

22. Lili E, Chatzistamatiou K, Kalpaktsidou-Vakiani A, Moysiadis T, Agorastos T. Low recurrence rate of high-grade cervical intraepithelial neoplasia after successful excision and routine colposcopy during follow-up. Medicine (Baltimore). 2018;97:e9719 https://doi.org/10.1097/MD.0000000000009719.

23. Wright TC Jr, Cox JT, Massad LS, Carlson J, Twiggs LB, Wilkinson EJ. 2001 consensus guidelines for the management of women with cervical intraepithelial neoplasia. J Low Genit Tract Dis. 2003;7:154-67 https://doi. org/10.1097/00128360-200307000-00002.

24. Miroshnichenko GG, Parva M, Holtz DO, Klemens JA, Dunton CJ. Interpretability of excisional biopsies of the cervix: cone biopsy and loop excision. J Low Genit Tract Dis. 2009;13:10-2 https://doi.org/10.1097/LGT.0b013e31817ff940.

25. Matsumura M, Ota T, Takeshima N, Takizawa K. Shimodaira-Taniguchi conization method: its utility and reliability. Int J Gynecol Cancer. 2010;20: 1025-30 https://doi.org/10.1111/IGC.0b013e3181e598bb.

26. Paterson-Brown S, Chappatte OA, Clark SK, Wright A, Maxwell P, Taub NA, et al. The significance of cone biopsy resection margins. Gynecol Oncol. 1992;46:182-5 https://doi.org/10.1016/0090-8258(92)90252-E.

27. Costa S, De Nuzzo M, Infante FE, Bonavita B, Marinelli M, Rubino A, et al. Disease persistence in patients with cervical intraepithelial neoplasia undergoing electrosurgical conization. Gynecol Oncol. 2002;85:119-24 https://doi.org/10.1006/gyno.2001.6579.

28. White $C D$, Macatol FR, DeJosef AB. Inflammatory cell infiltrate in the cervix as a predictor of residual cervical intraepithelial neoplasia after conization. J Reprod Med. 1992;37:799-802.

\section{Publisher's Note}

Springer Nature remains neutral with regard to jurisdictional claims in published maps and institutional affiliations. 